\title{
Analysis of seismic performance of the scale model of a rib-ring shallow spherical shell
}

\author{
Gao Zhan ${ }^{1, a}$, Jia Dongyun ${ }^{1, b}$, Liu Jianwen ${ }^{1, c}$ \\ ${ }^{1}$ Anhui University of Technology, Ma'anshan, China

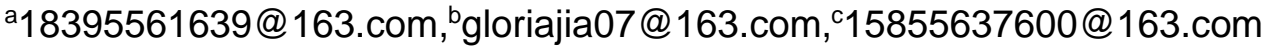

Keywords: rib-ring shallow spherical shell, natural vibration characteristics, time history analysis, dynamic response, gasholder

Abstract. The studying about the seismic performance of shallow and spherical shells with ribs and rings is very lack. So it is necessary to study its dynamic response under earthquake. In this paper, the finite element model is established by ANSYS software. The first 10 orders of natural frequency and mode shape of the shell structure are obtained by using the block Lansos method. The vibration law is analyzed. The seismic wave is selected based on the Code for seismic design. The elastic time history analysis is used to study the maximum displacement and stress of shallow spherical shells under earthquakes. The analysis results can provide a favorable theoretical basis for the engineering.

\section{Introduction}

With the development of productivity in our country, the storage tanks with large capacity and ribbed shell structures have been widely used. Gasholder is important building facilities in industrial production and people's lives, and their safety is also very important. The gasholder is a complex large-sized ribbed shell structure ${ }^{[1]}$. The top of the gasholder is a shallow and spherical shell with ribs and has good space performance. However, with the stricter anti-seismic requirements for building structures in China, the research about the seismic performance of shallow and spherical shells with ribs is lack. The displacement of vertical direction is greater than that of horizontal direction under the action of horizontal direction ${ }^{[2]}$. Numerical simulation and time history analysis are applied to analyze the top shell ${ }^{[3,4]}$. In the paper, establishing a scale model of the top shell of a $300,000 \mathrm{~m}^{3}$ gasholder by ANSYS software, the natural vibration characteristics and the dynamic response under earthquake are studied. The results can provide references for engineering practice.

\section{FEM Scale Model of Rib-ring Shallow Spherical Shell}

The top shell of the $300000 \mathrm{~m}^{3}$ gasholder is $6 \mathrm{~m}$ in height and $60 \mathrm{~m}$ in span. The 1:20 scale model, which has $3 \mathrm{~m}$ in span and $0.3 \mathrm{~m}$ in rise, is established by ANSYS software. The arrangement of ribs in the top shell is shown in Fig. 1

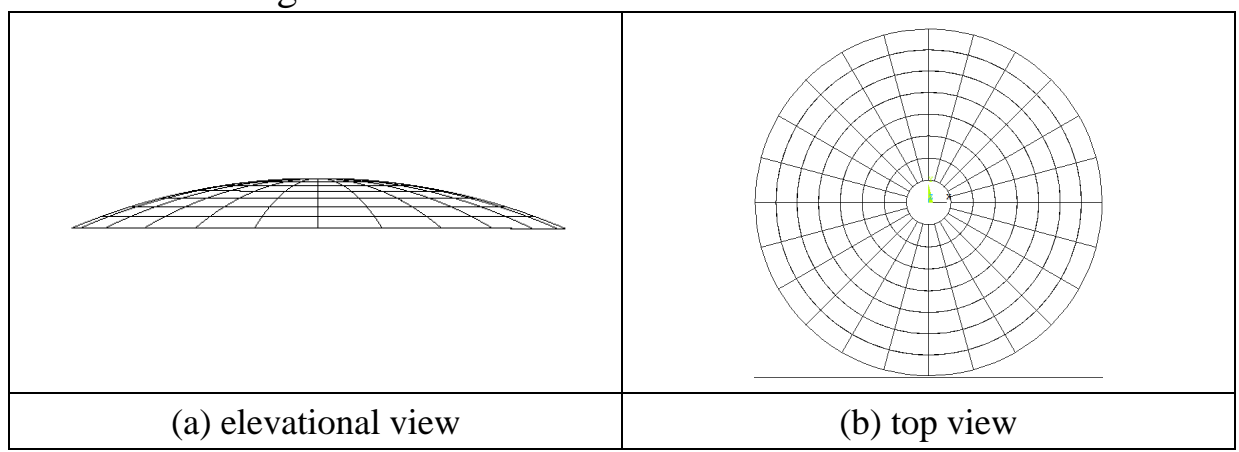

Fig.1 Arrangement of ribs in the top shell 
In finite element simulation, the element beam188 is selected for the radial ribs and circular ribs, which are C-channel steel with a section size of $10 \mathrm{~mm} \times 5 \mathrm{~mm} \times 0.3 \mathrm{~mm}$. The element shell181 is selected for shell, which is $0.4 \mathrm{~mm}$ steel plate. 24 radial ribs and 8 circular ribs are attached to the bottom surface of top shell. The nodes are rigid joints and the supports are three-way fixed. The material is Q235 steel with a density of $7850 \mathrm{~kg} / \mathrm{m}^{3}$.

\section{Analysis of Natural Vibration Characteristics of Top Shell}

The first 10 orders of natural frequency and mode shapes of the shell structure are obtained by Block Lansos method. The results are listed in Table 1, and the first 5 modes of the structure are shown in Fig.2.

Table1. The first ten natural frequencies

\begin{tabular}{|c|c|c|c|c|c|c|c|c|c|c|}
\hline order & 1 & 2 & 3 & 4 & 5 & 6 & 7 & 8 & 9 & 10 \\
\hline frequency[Hz] & 77.9 & 80.6 & 179.3 & 193.9 & 196.1 & 198.0 & 198.3 & 198.7 & 199.0 & 199.1 \\
\hline
\end{tabular}

From Table 1, it can be seen: 1) The natural frequencies of the first and the second order are close and lower. The dynamic response of the shell structure is dominated by the first two vibration modes. 2) The rest natural frequencies are similar and much higher. In order to ensure the accuracy of calculation, appropriate and enough modes of vibration must be taken because of complex dynamic characteristics of the shell structure.

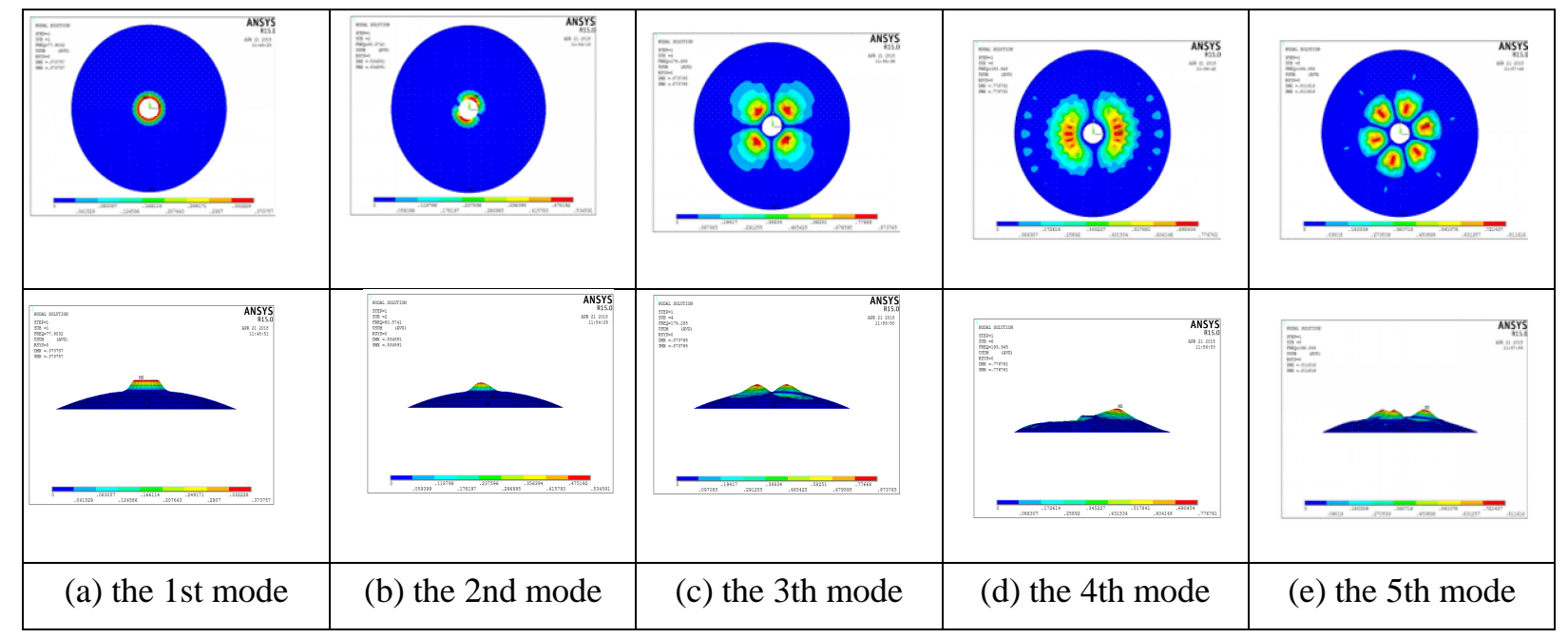

Fig. 2 The first five modes of vibration

Fig.2 shows that: 1) Due to the symmetry of the shell structure, the vibration modes of each stage are symmetric. 2) In the lower vibration modes, the maximum value appear near the center; in the higher vibration modes, the maximum value moves to internal region. 3) Vertical vibration is the main component.

\section{Selection of Seismic Wave}

The selection of seismic waves is particularly critical for analyzing elasto-plastic time history under the action of rare earthquakes. The seismic response caused by random input of different seismic waves may cause great differences. Based on Code for Seismic Design of Buildings (GB50011-2010) ${ }^{[4]}$, three seismic waves are selected: NorthernCalif-05 wave, San Fernando wave and La-Hollywood wave. The waveforms in the three directions are shown in Fig.3. Fig.4 shows the comparison between the average $\beta$ spectrum of the selected seismic waves and the standard $\beta$ spectrum. 


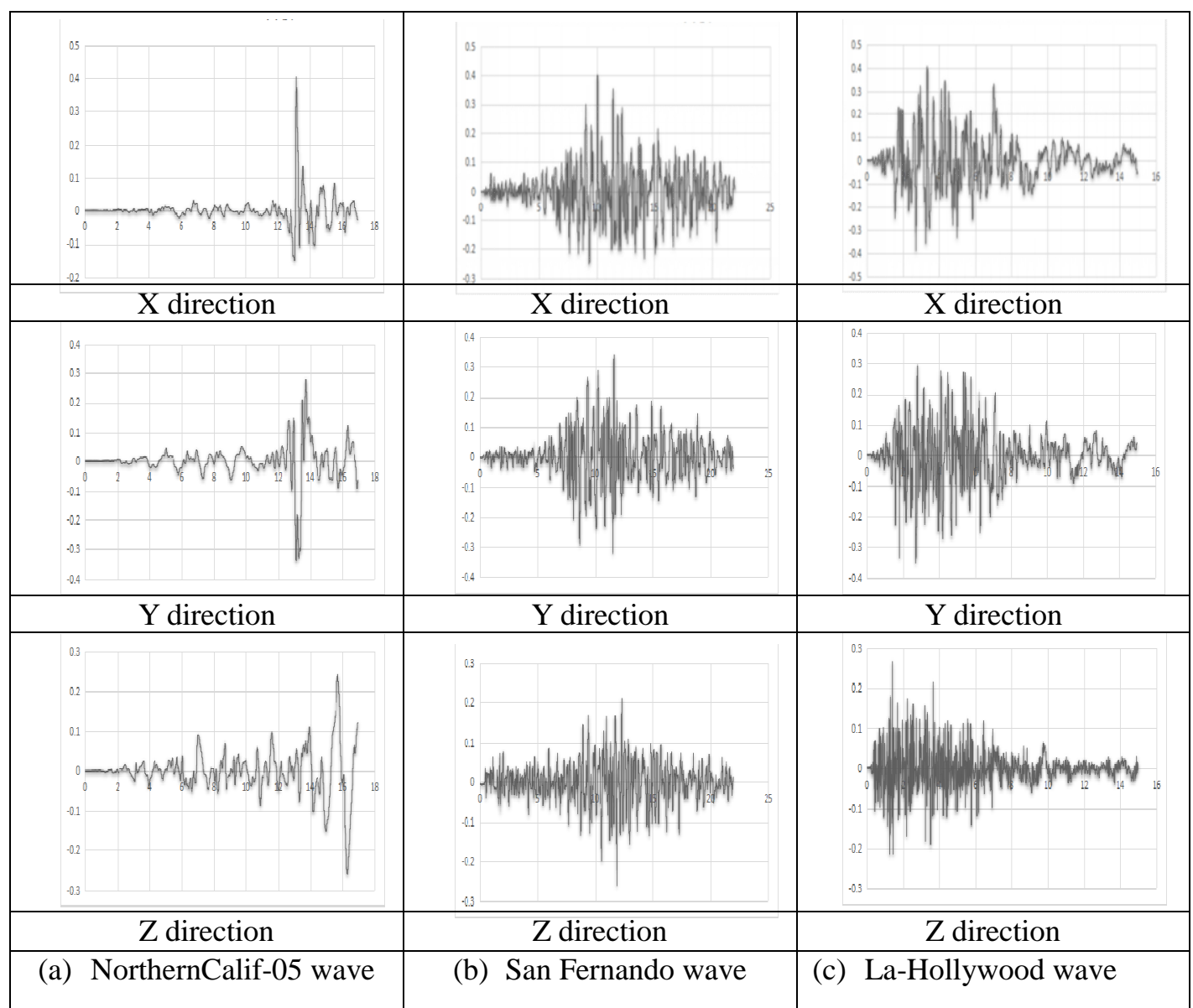

Fig. 3 the waveforms in the three directions of the three waves

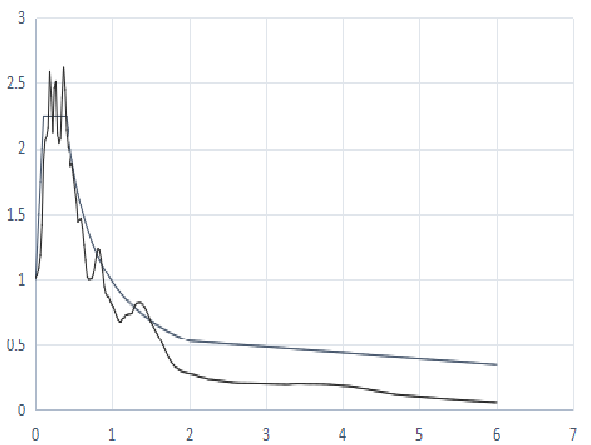

Fig. 4 Average $\beta$ spectrum of selected seismic waves and the standard $\beta$ spectrum.

\section{Elasto-plastic time history analysis of top shell under three-dimensional earthquake}

Simultaneously, the data of three-dimensional seismic acceleration are input into the finite element model and the rare earthquake calculation is performed to obtain the maximum displacement (shown in Fig.5).

The following conclusions can be drawn from Fig.5: 1) Under the three-way stimulus of three seismic waves, the vertical seismic response is much larger than the horizontal seismic response. 2) The maximum displacement are located near the center, which shows that the stiffness is weaker in this region. The result is similar to that of model analysis. 


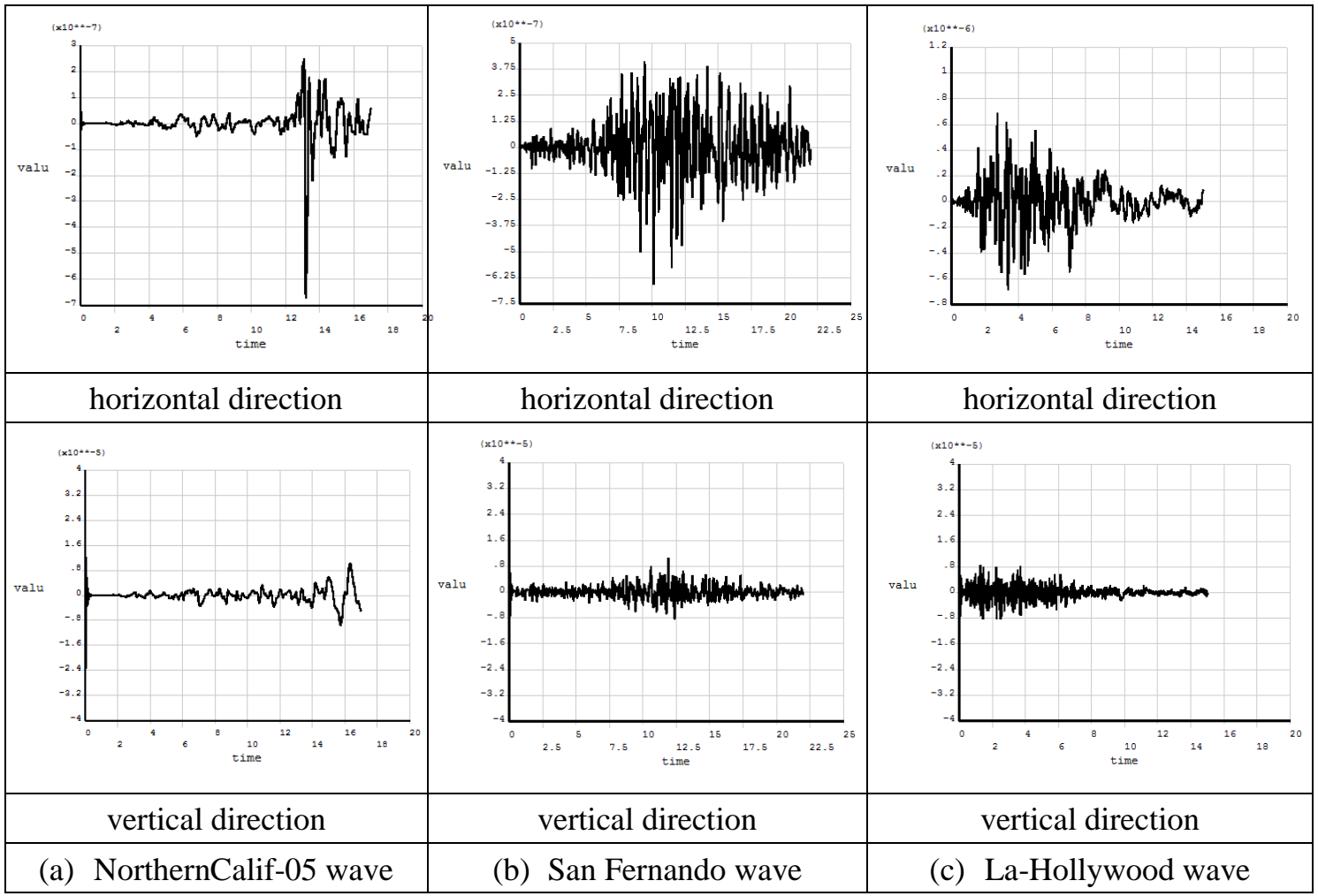

Fig.5 maximum displacement under three seismic waves

Table 2 Maximum displacement in horizontal direction and vertical direction

\begin{tabular}{|c|c|c|}
\hline Seismic wave & Horizontal direction $\left[10^{-7} \mathrm{~m}\right]$ & Vertical direction $\left[10^{-5} \mathrm{~m}\right]$ \\
\hline NorthernCalif-05 & 6.8 & 1.3 \\
\hline San Fernando & 6.4 & 1.2 \\
\hline La-Hollywood wave & 7.0 & 0.9 \\
\hline
\end{tabular}

The maximum horizontal and vertical displacement values of the three groups of seismic waves are listed in Table 2. The maximum displacement in horizontal direction is $7.0 \times 10^{-7} \mathrm{~m}$, and the maximum displacement in vertical direction is $1.3 \times 10^{-5} \mathrm{~m}$. Both of them can meet the normal use requirements of the gasholder.

\section{Conclusion}

The finite element modal of top shell of gasholder is established and modal analysis is performed to observe various modes. Three seismic waves are selected and elastic time history analysis is performed to obtain data of dynamic response. Through the results of analysis, the following conclusions can be obtained:

(1) The stiffness of members near center is weaker than that of other parts of the structure.

(2) The first two frequencies are similar, and there is a large difference between them and the higher order frequencies.

(3) Under the action of earthquake, the displacement response of the shallow spherical shell structure is dominated by vertical displacement. The maximum displacement is located near the center, which can meet the requirements of normal use of gasholder.

\section{Acknowledgements}

This work was financially supported by the Anhui Natural Science Foundation (1708085ME126). 


\section{References}

[1] Wang TAO. Seismic performance analysis and optimization design for gasholder ribbed shell structure. Anhui University of Technology, Ma'anshan, 2017

[2] Liu Jia. Analysis of Stress and Dynamical Characteristic of Large-Scale LNG Storage Tank Reticulated Shell Vault. Lanzhou University of Technology, Lanzhou, 2010

[3] Han Qing-hua, Liu Xi-liang: Seismic Analysis and Design of a Single Layer Spherical Lattice Shell with Large Depth-to-span Ratio and Openings. SPATIAL STRUCTURES. Vol.7 (2001),p. 52-56

[4]YU Jian-wei, Liu Xiao-ping: Parametric modeling method in ANSYS. Machinery. Vol.35 (2008),p. 21-22

[5]GB50011-2010, Code for Seismic Design of Buildings, 2010 